\title{
A Case Study of Clark's Strategies for Looking and Talking about Art Activities at the College Level
}

\author{
Kazuyo Nakamura
}

With the advent of the discipline-based art education (DBAE) movement, the content of art education has shifted from a studio-centered orientation to an art history, art criticism, aesthetics and studio art orientation. A report of the NAEA (National Art Education Association) indicates that $90 \%$ of school districts have moved to what they report to be a DBAE program (Hurwitz, 1990). One of the main goals of DBAE is to develop students' abilities to respond to art in ways that help them understand and appreciate art.

Although the NAEA report shows positive results of implementing DBAE, Wilson, Chapman, and Silverman found in the National Art Assessment on 9-, 13-, and 17-year olds that: "Most students do not know how to perceive and respond to works of art well enough to appreciate either their sensory qualities or their structures" (Lovano-Kerr, 1985). In addition, Short found in her research on 18 pre-service art teachers that $61 \%$ of them do not possess abilities to see relationships between factual knowledge and comprehensive, conceptual knowledge and strategies to select and transform relevant factual and conceptual knowledge in appropriate ways to respond to art (Short, 1995).

How pre-service art teachers teach about responding to art at the primary and secondary levels depends largely on their abilities to respond to art and how they were taught how to respond to art in their teacher education programs. Therefore, it is important in art teacher education programs to provide educational opportunities where students can learn how to respond to art, as well as develop effective ways of teaching to enhance such abilities.

This study sought to find useful strategies for teaching how to respond to art at the college level. The researcher analyzed Gilbert Clark's strategies of teaching in his course, 'Looking at and Talking about Art,' at the college level. Clark has taught this course for more than ten years, and analyzing Clark's strategies may be beneficial, at the college level, in establishing effective ways of teaching how to respond to art.

Wilson (1992) studied looking at and talking about art activities conducted by Clark at the middle school level. She observed six sessions and interviewed Clark and his students. Wilson consequently developed a tooking At and Talking About Art (LATA) theory, in which she systematized components of Clark's strategies used in looking at and talking about art activities. This study focused on Clark's teaching at the college level. Rather than figuring out and explaining components of his methodology, this study sought to understand the essential nature of Clark's strategies behind the components. 


\section{Methodology}

A qualitative case study methodology was employed to study the essential nature of Clark's strategies by looking at his ways of teaching the activities. Merriam (1988) stated that, "A qualitative case study is an intensive, holistic description and analysis of a single instance, phenomenon, or social unit" (p. 21). Clark's teaching strategies, which reflected his philosophy of art education and his teaching experiences, could be understood most effectively by examining holistically those strategies. Thus, a qualitative case study was determined to be a most appropriate research method. Data collection consisted of participant observation of the course taught by Clark, Looking at \& Talking about Art, interviews with Clark, and document analysis. All data collection procedures were conducted in 1996 by me as researcher; I also was enrolled in the same course as a student in Spring, 1994.

\section{Participant Observation}

The researcher entered the study as a participant-observer of the Looking at \& Talking about Art class. A participant observer's role entails ways of being present in everyday settings that enhance his or her awareness and curiosity about the interactions taking place in a particular context (Glesne \& Peshkin, 1992). The researcher began fieldwork in January 1996 and ended in April, 1996, after attending every session of the 1996 course. Sessions were held twice weekly for two hours in classroom in the School of Education at Indiana University. While the researcher observed looking at and talking about art activities in the class, data were collected by means of observational notes, audiotaping, and videotaping. A total of 18 sessions were videotaped and audiotaped and all questions and statements that Clark made during classes concerning, the context of each session, were transcribed.

A total of fourteen students, including five international students, participated in the class. They consisted of four undergraduate and seven graduate students whose major was art education, one graduate student whose major was elementary education, and two graduate students whose major was instructional technology.

\section{Interviews}

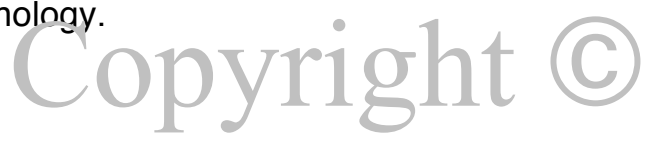

Interviews were conducted with Clark who was the instructor of the class Informal interviews were conducted after each class about the questions that arose during each participant-observation session. These questions usually concerned details of the instruction during a class session. Semi-structured interviews took place four times during the ongoing analysis of data. Broad questions were asked: What were Clark's main experiences as an art educator as well as a scholar, what was the content of looking at and talking about art activities in his class, and what were his instructional strategies for looking and talking about art? These interviews lasted from 15 to 50 minutes and were audiotaped and transcribed. 
In addition, interviews with three students who were in the course, were conducted. The purpose of these interviews was to confirm and refute the researcher's interpretation of nature of Clark's strategies, thus to enhance the trustworthiness of the interpretation.

\section{Document Research}

Articles and books about Clark's views of art education, obtained from Educational Resources Information Center (ERIC) and Indiana University Libraries' On-line Catalog (IUCAT), were examined. Data were collected concerning background information about Clark's scholarly history, which may have affected Clark's strategies of teaching looking at and talking about art activities.

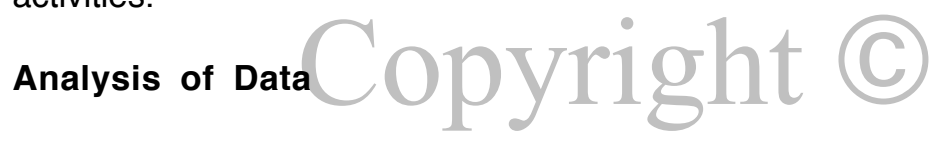

Transcripts of interviews and audiotapes of sessions of looking at and talking about art, field notes of all observations, and documents were analyzed using the constant comparative method in which all incidents were categorized according to similarities. These categories were constantly compared to each other in order to discover themes that adequately interpret the data (Glaser \& Strauss, 1967). Data analysis was done simultaneously with the data collection. As the researcher continued analysis, hypotheses were developed, modified, or abandoned. Revising categories continued throughout this process until the researcher was satisfied with the set of categories derived from the data.

\section{Establishment of Trustworthiness}

The researcher attempted to enhance the validity of research findings through triangulation of data (Lincoln \& Guba; 1985 Mathison, 1988).

Triangulation refers to a process of verifying data through multiple methods and sources. In this study, the researcher explored multiple data sources previously described, conducted member checks with Clark, and kept reflective notes throughout the course of this research (Peshkin, 1988). In addition, the researcher conducted informal interviews with students in the session, and compared results of this study with those in Wilson's (1992) study to enhance trustworthiness.

\section{Clark and the Crurse, Locking at \& Talking about Art}

Clark, the main subject for this study, has expert knowledge of and experience in teaching looking at and talking about art activities (Wilson, 1992). Clark had been considering how important it was to teach looking at and talking about art since he was an elementary school teacher. This thought was strengthened when he worked for the Kettering Project in the late 1960s, in which one of the key components of art curriculum was to include productive, critical, historical, and aesthetic aspects in studying art (Clark, 1984). After that, Clark experimentally started teaching the course, Looking at \& Talking about Art, when he was at the Ohio State University from 1971 to 1974. 
Clark saw that art education curriculum in general emphasized mainly studio art, and only casually dealt with art history, art criticism, or aesthetics. Even if students took art history courses at the college level, Clark observed that course content would be mainly memorization rather than discussion of works of art. Clark stated why he started the course, Looking at \& Talking about Art, at Indiana University, and how it was important to have such a course open to students majoring in art education:

We need teachers who can teach art criticism, art history, and aesthetics, as well as teach studio art. If you look at the program that they have here at this university, ninety percent of the program is studio art. They don't study art criticism, they don't study aesthetics, they might study a little bit of art history, but not very much. If they do study a bit of art history, it is memorizing hundreds of slides titles in order to take a test. That's not good art history, either. That's not the model we want people to go out and do in the schools. As a consequence of this view, the goals of his Looking at and Talking about Art course were:

Nerbal facility. There is a certain amount of problem-solving. There is no question when people take the course and come out of the course, they look at art more deeply. They look at art differently. They see more in the art work than they did before. So there are some perceptual skills they learn. Although they are not going to be the same among all students, there is no question that students become more comfortable talking about work of art. That's the major goal.

In the Looking at \& Talking about Art course, the main goals were to become comfortable discussing works of art and developing verbal facility, which also included problem-solving and enhanced perceptual skills. Clark believed that these abilities were essential and fundamental in learning productive, historical, critical, and aesthetic aspects of art, and that it was important for art educators to help future art teachers develop these abilities.

Themes That Emerged From Data Analysis. The themes which helped understand how and what Clark taught in looking at and talking about art activities emerged from the data analysis. These were the instructor's: (1) role as a facilitator of discussions, (2) use of open-ended questions, (3) use of structured questions from simple to complex levels, and (4) development of students' skills instead of relating facts to interpret art images.

\section{Instructor's Role as a Facilitator of Discussions}

Clark's role in looking at and talking about art activities was a facilitator of discussions. The center of all activities was always students, not the instructor. Throughout the observed sessions, Clark never corrected students' responses to his questions. Clark explained the reason for this: "If you correct answers at the very beginning of the discussion, you kill the conversation, because you become an authoritative answerer in the classroom." Instead, Clark accepted every student's response, and frequently showed positive attitudes to students who were talking (Wilson, 1992). These attitudes appeared in both verbal and physical expressions. For example, Clark often encouraged students to talk more 
by saying, "OK," "Yeah," "Yes," "Right," "True," and "Good," and made physical gestures such as nodding and facial expressions of satisfaction. In this way, Clark facilitated students' talking more about the work of art under discussion than they normally would do if the instructor was prominent in the questioning.

Clark's role in looking at and talking about art activities was a facilitator to stimulate discussion flow. Clark saw himself as a supporter for students to talk more about works of art rather than an authoritative instructor, who corrected students' interpretations of works of art by giving correct information.

\section{Open-Ended Nature of Questions}

An open-ended question strategy was also essential in Clark's directing looking at and talking about art activities (Wilson, 1992). The questions posed by Clark were almost all open-ended questions, as were his comments to the students. Examples of such questions and comments were: "what is there in this image?," "what do you mean?," "what about (a word expressed by a student)?," "what does your expression mean?," "verbalize your head shaking," and "say more." Clark explained the meaning of such open-ended questions in educational settings:

I want them [students] to feel comfortable in a situation where the academic situation is to answer open-ended questions, not closedended questions, speculate about the answers, theoretical answers, possible answers, not the right answers. So part of the outcome of looking and talking about art I think is for them to become comfortable to say, to be able to say themselves that I have things I can contribute. I can speculate with other people, speculate about the image meaning, also speculate about their own reactions to the image and other people.

Such open-ended questions and comments, which did not demand right or wrong answers, helped students feel comfortable looking at and talking about art. Further, they helped individual students became more conscious of their reactions, critically examine them, verbalize more, and learn different points of view from other students. However, when every student's response is accepted in discussion, there is a danger that students' interpretations in discussion may not be valid. Clark explained about this issue:

If you introduce students to an artwork, they may misinterpret it, you do not want to jump in right away and say, "that's wrong." That's going to make them not willing to interpret it. What you want to do is to go around the room to people until somebody interprets more rightly, and then you reinforce it. Then, other kids realize, "I was not right," when you reinforce that answer. But you have not told them that. It's a touchy point and a difficult task. In order to do this, teachers should do homework before they bring an art work in a classroom. What happens when teachers do not do their homework, when kids misinterpret an artwork, they may reinforce a wrong answer. 
As Clark explained, teachers are required to study works of art before they bring them into discussions so that they are able to judge carefully what students say about the works. In the practical situation, Clark led the discussion to a right direction by picking up right elements included in students' comments into questions, which helped students' discussion go further and deeper towards a right interpretation.

\section{Structured Questions from the Simple to Complex Levels}

Questions about an art image were structured to make students look at and talk about the image on simple to more complex levels. At the first level of discussion, questions were asked to encourage students to perceive and identify simple properties of the image, such as colors and shapes. At the second level, questions were asked to support students in seeing relationships among simple properties discussed at the previous level, and thus perceive organizational or compositional structures in an image. At the third level, questions were asked to encourage students to bring outside knowledge to the image, or recognize a style, an artist, or an historical period. At the forth level, questions were asked to help students make inferences, interpretations, and evaluations (see Figure 1).

Figure 1. Structure of Questioning

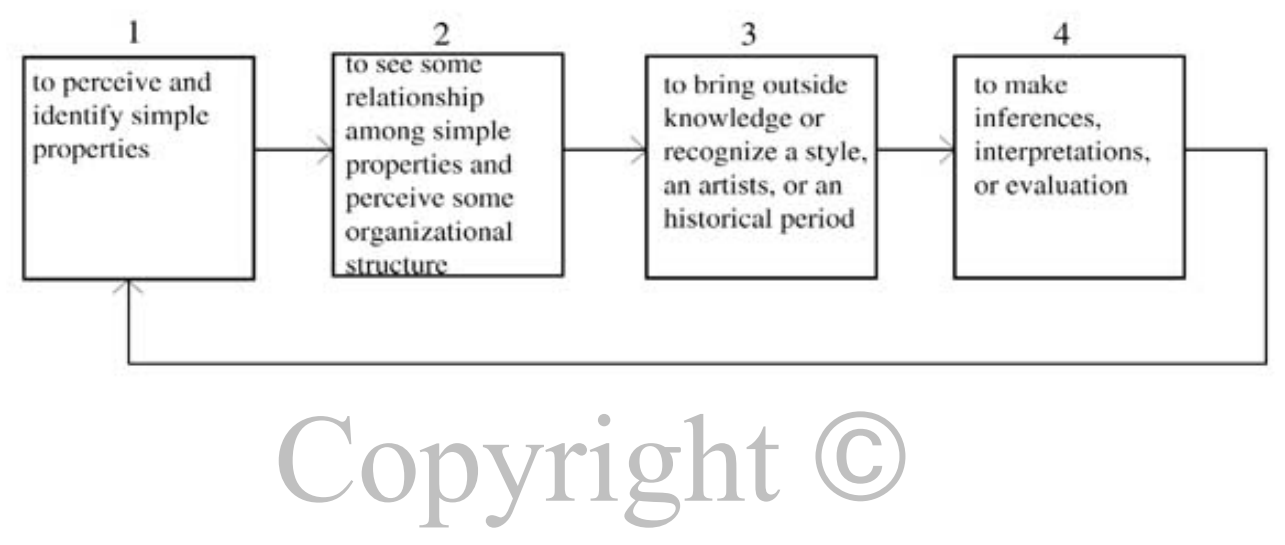

There were no clear boundaries among the four levels, and the system was circular in that newly learned skills were used in interpreting other images. Principally, all questions at every level were sequential based on students' responses. Clark carefully grasped points that emerged in students' comments, and paraphrased them into the next question. Levels of discussion were sensitively and carefully adjusted by Clark's diagnosis of students' abilities presented in their responses. If Clark judged that students' abilities were not mature enough to interpret an art image, Clark would prefer that students' stayed longer at the fundamental levels. On the other hand, if it looked as if students were ready to interpret an art image, Clark let students go to the higher levels of questioning. 


\section{Use of Skills Instead of Facts to Interpret Art Images}

What students learned in the looking at and talking about art activities directed by Clark was use of a set of skills rather than simple recall of fragmentary art facts in order to read and interpret art images. Students learned how to meditate about and question about comments made by themselves and others applying their knowledge and visual information available from presented images. In the sessions, Clark rarely gave information such as artists' names and dates to students. Instead, Clark provided students with opportunities in which they could practice applying their knowledge and personal experiences in order to interpret presented art images. For example, when students learned vocabulary words such as "realistic" and "stylistic," they questioned, examined, and explored their definitions of the words. They applied their definitions to presented images and discussed them with other students, instead of being given a "correct" definition of the words by the instructor. Clark commented about this strategy:

If I start volunteering information about dates, artists, and style, what are students' expectations? They don't look for this kind of information.

When they need information, they ask. Until they ask, it is not important. If curiosity says that they want to look that up, they are going to remember it.

Clark believed that keeping information given by an instructor to a minimum let students look into presented art images more, try to find out the information from the images, and apply their knowledge and personal experiences to the images. Thus, Clark hoped that students would acquire skills, attitudes, and confidence in order to read visual images, and that they would use these in doing further research to learn more about the images they were studying.

\section{Conclusion}

The purpose of this study was to understand nature of Clark's strategies of teaching looking at and talking about art activities. It was hoped that this study would provide useful consideration for art teachers in designing and practicing teaching the similar activities. In conclusion, Clark's strategies are useful to enhance these students' abilities. They are higher-order thinking, critical thinking, and visual perception.

What students practice in the looking at and talking about art activities directed by Clark is applying their knowledge about art and personal experiences in order to interpret presented art images. Students do not simply recall fragmentary pieces of information. Instead, when students response to images, students reflect themselves and their personal experiences connecting knowledge of art with them. In other words, they reconstruct their personal experience and knowledge of art through looking at and talking about art activities. Such activities demand higher-order thinking from students. 
Further, questions not requiring a right answer put students in the situation, where they must examine and justify interpretations against other possible interpretations made by other students. Instead of accepting a given right answer passively, they must find reasons for their interpretations actively using available information from presented art images and their knowledge. Such process requires students to think critically.

In addition, in the looking at and talking about art directed by Clark, little information about presented art images from the instructor is available. As a consequence, students' attitudes of expecting an instructor to give information is challenged. Instead, students' attitudes of looking hard and carefully at presented visual images are developed. Thus, Clark's strategies help students enhance their visual perception skills.

The students who took the course, Looking at \& Talking about Art, expressed how the course was meaningful to them. The main reason was that they developed skills and abilities to read visual images without written information. For example, a student, who used to pass over works of art quickly in an art museum, said that she came to look at a work of art longer than before, tried to find the meaning in it, and explained to her friends in an art museum. In an interview, one of the students in the class said:

The class is beneficial to me in a sense that it helped me deal with art at one level of looking and talking to new understanding. He [Clark] teaches pedagogy versus lectures. There is a sequence of questioning. When you answered a question, he wouldn't stop by saying 'yes' or 'no,' instead he required you to prove more from you. It requires higher-level of thinking. It is clear that he is one of the best teachers.

\section{References}

Chapman, L., \& Newton, C. (1990). 1990 Teacher viewpoint survey: The results and comparisons. School Arts, 90(1): 41-45.

Clark, G. (1991). Examining discipline based art education as a curriculum construct. Bloomington, IN: ERIC/ART.

Clark, G., Day, M., \& Greer, D. (1987). Discipline-based art education: Becoming students of art. Journal of Aesthetic Education, 21(2): 129-193.

Clark, G. (1984). Beyond the Penn State Seminar: A critique of curriculum. Studies in Art Education, 25(4): 226-231.

Clark, G., \& Zimmerman, E. (1978). Art/design: Communicating Visually. Blauvelt, NY:Art Education.

Clark, G., \& Zimmerman, E. (1978). A walk in the right direction: A model for visual arts education. Studies in Art Education, 19(2): 34-49.

Marilyn Zurmuehlen's Working Papers In Art Education 1998-1999 
Glaser, B., \& Strauss, A. (1967). The discovery of grounded theory: Strategies for qualitative research. Chicago: Aldine.

Glesne, C., \& Peshkin, A. (1992). Becoming qualitative researchers: An introduction. New York: Longman.

Hurwitz, Al. (1990). Chronicle: A report to NAEA President Ameria Sanchez. Art Education, 43(1): 12-18.

Lincoln, Y. S., \& Guba, E. G. (1985). Naturalistic inquiry. Beverly Hills, CA: Sage. Lovano-Kerr, Jessie. (1985). Implications of DBAE for university education. Studies in Art Education, 26(4): 216-223.

Mathison, S. (1988). Why triangulate? Educational Researcher, 17(2) :13-17.

Merriam, S. (1988). Case study research in education: A qualitative approach. San Francisco: Jossey-Bass.

Peshkin, A. (1972). In search of subjectivity-one's own. Educational Researcher, 17(7): 17-22.

Short, G. (1995). Understanding domain knowledge for teaching: Higher-order thinking in pre-service art teacher specialist. Studies in Art Education, 36(3): 154-169.

Southwest Regional Laboratory Elementary Art Program (1991). Bloomington, In PhiDelta Kappar.

Wilson, M. (1992). Analysis of expert and leaner interactions during looking at and talkingabout art activities. Dissertation Abstract, 53(7). (University Microfilms No. AAT 9231636).

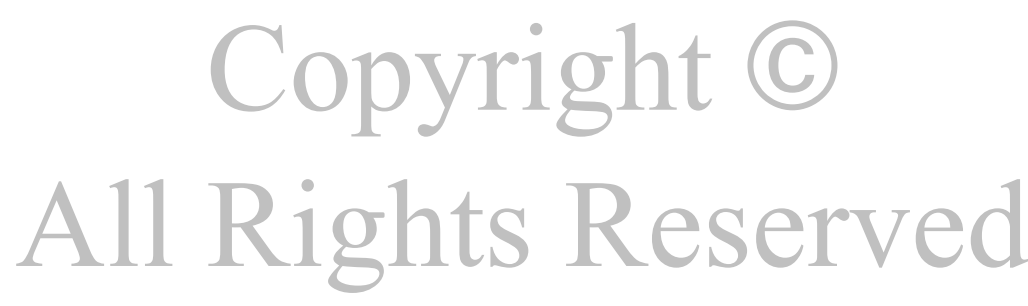

